\title{
Therapeutic intraspinal stimulation to generate activity and promote long-term recovery
}

\author{
Sarah E. Mondello ${ }^{1,2,3}$, Michael R. Kasten ${ }^{1}$, Philip J. Horner ${ }^{2,4}$ and Chet T. Moritz ${ }^{1,3,4,5 *}$ \\ ${ }^{1}$ Department of Rehabilitation Medicine, University of Washington, Seattle, WA, USA \\ 2 Department of Neurological Surgery, University of Washington, Seattle, WA, USA \\ ${ }^{3}$ Center for Sensorimotor Neural Engineering, University of Washington, Seattle, WA, USA \\ ${ }^{4}$ Graduate Program in Neurobiology and Behavior, University of Washington, Seattle, WA, USA \\ ${ }^{5}$ Department of Physiology and Biophysics, University of Washington, Seattle, WA, USA
}

\section{Edited by:}

Mesut Sahin, New Jersey Institute of Technology, USA

Reviewed by:

Reinhold Scherer, Graz University of Technology, Austria

Andrew Jackson, Newcastle

University, UK

\section{*Correspondence:}

Chet T. Moritz, Departments of

Rehabilitation Medicine and

Physiology and Biophysics, School

of Medicine, UW Medical Center,

University of Washington, 1959 N.E.

Pacific Street, PO Box 356490,

Seattle, WA 98195, USA

e-mail:ctmoritz@uw.edu
Neuroprosthetic approaches have tremendous potential for the treatment of injuries to the brain and spinal cord by inducing appropriate neural activity in otherwise disordered circuits. Substantial work has demonstrated that stimulation applied to both the central and peripheral nervous system leads to immediate and in some cases sustained benefits after injury. Here we focus on cervical intraspinal microstimulation (ISMS) as a promising method of activating the spinal cord distal to an injury site, either to directly produce movements or more intriguingly to improve subsequent volitional control of the paretic extremities. Incomplete injuries to the spinal cord are the most commonly observed in human patients, and these injuries spare neural tissue bypassing the lesion that could be influenced by neural devices to promote recovery of function. In fact, recent results have demonstrated that therapeutic ISMS leads to modest but sustained improvements in forelimb function after an incomplete spinal cord injury (SCI). This therapeutic spinal stimulation may promote long-term recovery of function by providing the necessary electrical activity needed for neuron survival, axon growth, and synaptic stability.

\section{CERVICAL INTRASPINAL MICROSTIMULATION}

Artificial stimulation via electrodes placed within the spinal cord parenchyma, termed intraspinal microstimulation (ISMS), is a promising technique for activating the spinal cord distal to an injury. ISMS may confer dual benefits of both reanimation of paralyzed limbs, as well as promoting plasticity leading to long-term recovery of function that outlasts the stimulation. Pioneering work demonstrated that intraspinal stimulation (ISMS) of the lumbar spinal cord is capable of directly evoking a range of hindlimb movements (Giszter et al., 1993; Mushahwar and Horch, 1998; Lemay and Grill, 2004). These movements often occur in functional synergies, or activate reflex circuits to produce complex movements (Tresch and Bizzi, 1999; Mushahwar et al., 2002).

Recent work from our group and others explores the potential for cervical intraspinal stimulation to restore hand and arm movements (Moritz et al., 2007; Zimmermann et al., 2011; Sunshine et al., 2013). Cervical ISMS evokes a rich variety of forelimb movement both before and after injury (Sunshine et al., 2013), and also confers modest but sustained improvements in forelimb function that persist beyond the period of stimulation (Kasten et al., 2013). In this perspective we summarize the ability of intraspinal stimulation to both directly evoke movements and to promote long-term recovery. By contrast, we compare results from studies where stimulation is applied to the dorsal surface of the spinal cord, termed epidural stimulation (Figure 1). We focus on cervical intraspinal stimulation and highlight its potential for restoring critical movement to the hands and arms, both directly and via re-regulation of spinal circuits surrounding an injury.

\section{THE PRESSING NEED FOR TREATMENT OF CERVICAL SPINAL CORD INJURIES}

Among individuals with spinal cord injury (SCI), incomplete injury to the cervical spinal cord is the most common diagnosis (NSCISC, 2013). Restoration of hand and arm function is the highest treatment priority for individuals with cervical spinal cord injuries, 5-fold more important than restoration of other functions lost to paralysis (Anderson, 2004). Despite this high priority, there are very few treatment options to bypass or repair the injured cervical spinal cord. Notable functional improvements have been demonstrated using combinatorial treatment strategies (Houle et al., 2006) or motor rehabilitation (Wang et al., 2011) following cervical hemisection or dorsal column lesion, respectively. The majority of clinical cases, however, are more complex contusion injuries with radiating secondary injury, demyelination and progressive axonal pathologies (Mctigue et al., 1998). Incomplete spinal cord injuries offer the distinct treatment advantage of axons that bypass the injury site and may not require long distance regeneration for restoration of function. This spared tissue could provide the crucial substrate for repair of conduction if it can be co-opted to transmit functionally useful signals around the injury.

\section{LEVERAGING INTRASPINAL CIRCUITS FOR RECOVERY FROM INCOMPLETE LESIONS}

There is promising evidence for partial recovery following incomplete injuries that highlights the substantial capacity for plasticity of intraspinal circuits. For example, spinal interneurons sprout and form functional synaptic connections with motor 


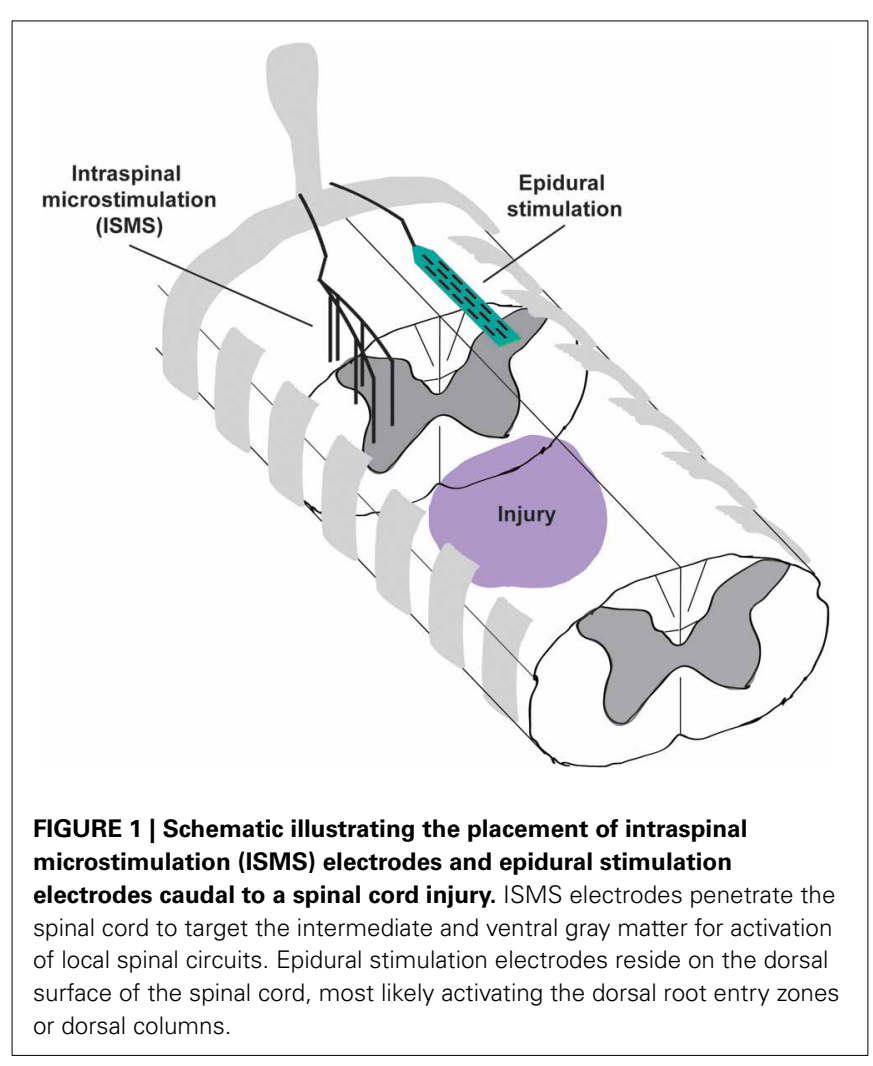

neurons across a midline transection injury (Fenrich and Rose, 2009). Additionally, damaged corticospinal tract axons sprout above a dorsal hemisection forming new synaptic connections with propriospinal neurons that bypassed the lesion site (Bareyre et al., 2004). The functionality of this new circuitry was confirmed electrophysiologically and via improvement in locomotion. Indeed, humans with chronic, moderate incomplete SCI have also demonstrated substantial recovery of function following intensive motor retraining (Harkema et al., 2011) that can be maintained for several years (Behrman et al., 2008; Fox et al., 2010). These results highlight the capacity for rewiring of spinal circuits around an incomplete lesion, especially in younger subjects with perhaps more flexible synaptic connections (Pizzorusso et al., 2002).

With the substantial capacity of the spinal circuitry to remodel after incomplete injury, an underappreciated application of ISMS may be to promote or guide this plasticity by providing the necessary electrical activity needed for recovery of these orphaned spinal circuits. In the following section we review the substantial evidence demonstrating the importance of electrical activity for the recovery of neural networks after injury.

\section{IMPORTANCE OF ACTIVITY FOR NEURAL NETWORK RECOVERY}

Neuronal activity is an important regulator of multiple components of the nervous system, including the critical barriers to neuronal survival, differentiation, axonal growth, and synaptogenesis (For reviews see Spitzer, 2006; Borodinsky et al., 2012; Morimoto et al., 2012). The influential role of activity begins during the early stages of development and continues in the mature nervous system. This section describes the benefits of electrical activity with the goal of promoting recovery of the adult central nervous system after injury.

\section{NEURAL ACTIVITY ENHANCES SURVIVAL AND DIFFERENTIATION}

Numerous data suggest that activity increases neuronal survival. For example, chronic electrical stimulation leads to increased survival of spiral ganglion cells after the application of a highly excitotoxic drug (Lousteau, 1987; Hartshorn et al., 1991). Multiple potential mechanisms may underlie this neuroprotective effect. The expression of a subset of genes that make neurons more resistant to stressful conditions, the activity-regulated inhibitors of death genes, are upregulated by synaptic activity, as detected in hippocampal neurons (Zhang et al., 2007; Tan et al., 2012). Furthermore, there is activity-regulated coupling between vascular cells and neurons critical for maintaining neuronal health and survival. For instance, numerous types of cortical neurons have shown that as they become more active, the blood flow and permeability of the blood brain barrier increases (for review see Leybaert, 2005) leading to greater delivery of oxygen, glucose, and other critical energy substrates (Cox et al., 1993; Harder et al., 1998; Iadecola and Nedergaard, 2007). The upregulation of brain derived neurotrophic factor (BDNF) is also enhanced by electrical activity (Al-Majed et al., 2000a). BDNF both increases spinal motoneuron synaptic plasticity (Al-Majed et al., 2000b, 2004), and protects neurons against oxidative DNA damage-induced death, as shown in cortical neurons (Yang et al., 2013). Several cyclic adenosine monophosphate (cAMP)-dependent mechanisms are similarly upregulated by activity and increase cell survival and axonal growth in retinal ganglion cells (Shen et al., 1999; Goldberg et al., 2002). Similar cAMP-dependent mechanisms enhance myelination in dorsal root ganglion cells (Malone et al., 2013). These effects are not necessarily restricted to just those neurons that are activated; activity-dependent neuroprotection has been shown to extend to regions beyond the field of neural activity in spiral ganglion cells (Leake et al., 1991). Thus, increasing the survival and participation of viable neuronal populations could lead to the formation of a circuit capable of bypassing an incomplete lesion and restoring a greater variety of motor and sensory functions.

\section{AXONAL GROWTH AND ELONGATION ARE POSITIVELY REGULATED BY NEURAL ACTIVITY}

Axonal growth may be critical for the formation of new circuits after SCI, and is also largely regulated by activity. In vitro, acetylcholine and glutamate attract growth cones into specific directions in a calcium dependent manner (Zheng et al., 1996). Furthermore, motoneurons from a mouse model of spinal muscular atrophy with reduced spontaneous calcium transients exhibit reduced axonal growth and growth cone size (Jablonka et al., 2007). Other studies show that the frequency of rhythmic bursting in the embryonic spinal cord affects the dorso-ventral and antero-posterior path-finding of developing axons (Hanson and Landmesser, 2006). In the adult nervous system, exogenously induced electrical activity increases the expression of the axongrowth associated gene GAP-43 in axotomized sensory and motor neurons, which in turn leads to the increased speed and accuracy 
of motor axon regeneration and reinnervation (Al-Majed et al., 2000a). Additionally, acute stimulation of ventral spinal cord cell transplants following sciatic nerve denervation leads to an increase in the number of myelinated axons and functionally innervated muscles (Grumbles et al., 2013). These studies suggest that inducing activation of spinal circuitry after injury may significantly increase axonal growth and regeneration, as well as the specificity of the circuit itself, leading to greater functional recovery.

\section{NEURAL ACTIVITY INDUCES SYNAPTOGENESIS AND DENDRITE STABILITY}

Synaptogenesis and novel dendrite stabilization is necessary for functionally restorative network formation after SCI. Activity is known to strongly regulate dendrite stabilization during development. For example, developing dendrites stabilize in response to cholinergic neurotransmission and local calcium-induced calcium release in the early stages of synapse formation (Lohmann et al., 2002). Furthermore, during the developmental phenomena of synaptic competition, synapses that are the most proficient at inducing postsynaptic activity remain viable while ineffective synapses are permanently removed (Balice-Gordon and Lichtman, 1994; Buffelli et al., 2003). The recruitment of progranulin to synapses along axons, which promotes synapse formation (Tapia et al., 2011; Petkau et al., 2012) increases in the presence of neuronal activity, indicating an activity-dependent regulation of synapse number and structure (Petoukhov et al., 2013). Enhancing the activity of neural circuits caudal to the injured spinal cord may both increase synaptogenesis, and act to stabilize new circuitry once it is formed.

Taken together, these studies strongly demonstrate that neural activity is necessary to promote long-term recovery of functional circuits after SCI. Intraspinal stimulation is one potential method for introducing this activity, either with the goal of directly reanimating the limbs, or perhaps ideally to promote sustained recovery of function.

\section{EVIDENCE FOR BENEFIT OF ELECTRICAL STIMULATION AFTER SPINAL CORD INJURY \\ DIRECT BENEFITS OF SPINAL STIMULATION \\ Intraspinal microstimulation (ISMS) of the cervical spinal cord}

Stimulation within the spinal cord activates local spinal networks in specific patterns to evoke functional movements. Building on extensive work demonstrating the ability of ISMS within the lumbar spinal cord to evoke standing and stepping movements (Mushahwar and Horch, 1998; Mushahwar et al., 2002, 2004), we have demonstrated that forelimb movements can also be evoked by ISMS delivered to the cervical spinal cord in non-human primates (Moritz et al., 2007). Zimmermann et al. (2011) then elegantly demonstrated that a reach and grasp movement could be re-animated by combining stimulation of multiple locations within the spinal cord of the anesthetized primate.

More recently we explored the forelimb movements evoked by cervical ISMS both before and after injury in a clinically-relevant rodent model of mid-cervical contusion injury (Sunshine et al., 2013). A wide variety of somatotopically organized forelimb movements could be evoked prior to injury from throughout the cervical spinal cord. Following injury, there was a transient period lasting approximately 3 weeks where movement variety was dramatically reduced. By 6 and 9 weeks after injury, however, a variety of movements could again be evoked via cervical ISMS, which were not statistically different from the effects prior to injury (Sunshine et al., 2013).

\section{Electrical stimulation after spinal cord injury improves motor function}

Electrical stimulation applied to the epidural surface of the spinal cord shows great promise for directly improving motor function after SCI. Epidural stimulation of the lumbar spinal cord can facilitate stepping movements after complete spinal transection, especially when combined with serotonin agonists and movement of a motorized treadmill underfoot (Ichiyama et al., 2005; Gerasimenko et al., 2008; Edgerton and Harkema, 2011). When combined with robotic assistance and motor training over complex surfaces, epidural stimulation also appears to facilitate the formation of a relay circuit bypassing a complex, staggered lesion in animal models (Courtine et al., 2008; Van Den Brand et al., 2012). In addition, an individual with American Spinal Injury Association (ASIA) grade $B$ incomplete injury was able to volitionally move his legs and support body weight during the activation of surgicallyimplanted epidural stimulation (Harkema et al., 2011). While these examples are inspiring, with the exception of important autonomic functions, improvements in skeletal motor function did not persist beyond the period of stimulation in this landmark study. As described below, lasting improvements in spinal circuit function have been noted after stimulation delivered to the brain, muscles, and intraspinal locations after injury.

\section{PERSISTENT BENEFITS OF ELECTRICAL STIMULATION AFTER INJURY}

Electrical stimulation applied to the cortex or brainstem after selective SCI promotes axon sprouting (Brus-Ramer et al., 2007) and improves motor function persisting beyond the period of stimulation (Carmel et al., 2010). In addition, electrical stimulation of fiber tracts in the pyramids or spinal white matter promotes sprouting and maintenance of ipsilateral spinal connections that are otherwise pruned during development (Salimi and Martin, 2004). In an early case study using epidural stimulation applied to the lumbar spinal cord, an individual with incomplete (ASIA C) SCI improved functional walking, with some motor benefits persisting beyond the period of stimulation (Herman et al., 2002). Since new connections are formed spontaneously after injury but subsequently lost if they do not project below the lesion (Bareyre et al., 2004), intraspinal stimulation caudal to the injury may be key to creating and maintaining a network of connections bypassing an incomplete spinal injury.

Trains of electrical stimulation delivered to peripheral nerves have been shown to substantially enhance function of both motor and sensory axons following nerve transection and subsequent surgical repair (Brushart et al., 2002, 2005). Functional electrical stimulation (FES) applied to muscles may also promote plasticity and circuit re-organization (reviewed in Barbeau et al., 2002). 
FES applied to the hindlimb muscles after SCI provides lasting improvements in gait (Jung et al., 2009), and also reduced muscle tone and improved spasticity (Mirbagheri et al., 2002). Notably, we have observed substantial reductions in tone of the injured forelimb in rodents receiving long-duration intraspinal stimulation below the injury, which likely contributes to their improved functional abilities that persist beyond the period of stimulation (Kasten et al., 2013).

\section{THERAPEUTIC BENEFITS OF ISMS}

Therapeutic ISMS of the cervical spinal cord evokes complex and often highly-functional synergies, but we also have recent evidence that stimulating the spinal cord below an injury improves motor function with benefits lasting beyond the period of stimulation (Kasten et al., 2013). Animals received a lateralized contusion injury in spinal cord segment C4, and ISMS electrodes were implanted caudal to the lesion 3 weeks later in segments C6C7 (Figure 1). Beginning 4 weeks after injury, animals received therapeutic intraspinal stimulation for $7 \mathrm{~h} /$ day, 5 days/week. Recovery was measured using the precision forelimb reaching task (Schrimsher and Reier, 1992; Mckenna and Whishaw, 1999), in all cases without the presence of stimulation.

In a particularly interesting example, an animal in the stimulated group recovered to $75 \%$ of pre-injury reaching ability within just 4 weeks (Figure 2). Notably, stimulation in this animal was discontinued after week 5 due to implant failure, providing the opportunity to observe lasting recovery with no further stimulation. Although reaching scores reduced immediately upon halting daily stimulation, success rates stabilized well above pretreatment levels and those of unstimulated animals (Figure 2), suggesting a long-term or therapeutic benefit from ISMS (Kasten et al., 2012).

Animals that continued to receive therapeutic ISMS for the remainder of the 12 weeks treatment period also significantly outperformed their unstimulated counterparts (Kasten et al., 2013).

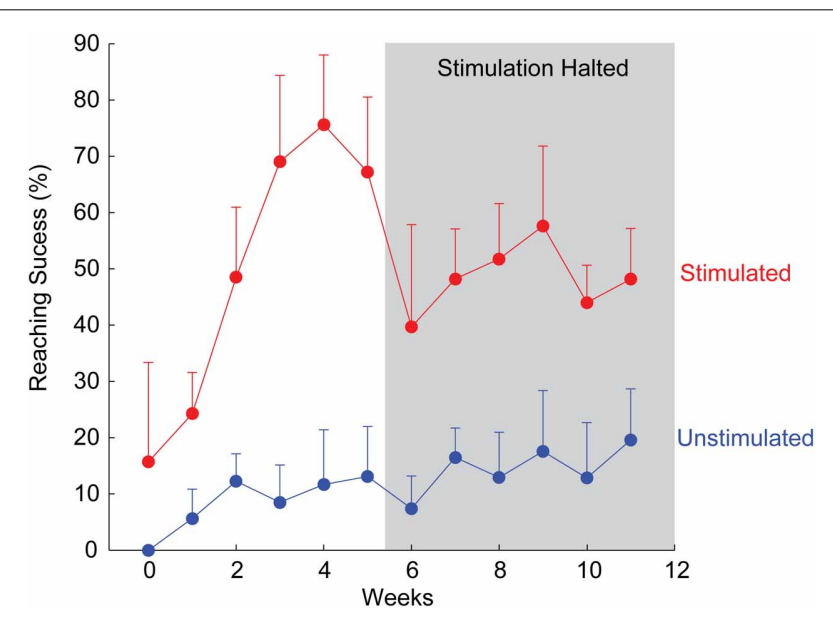

FIGURE 2 | Example of rapid recovery of forelimb reaching ability for one animal receiving therapeutic ISMS, compared to an unstimulated animal. After 5 weeks, stimulation was halted due to implant failure, allowing examination of sustained recovery with no further stimulation. Mean + SD for each animal.
Detailed examination of the reaching components revealed the greatest improvements in the ability to aim and advance the arm in the precision forelimb reaching task, consistent with improved coordination and proprioception. Thus, therapeutic spinal stimulation appears to provide the necessary electrical activity missing after injury and leads to the re-regulation of neural circuits deprived of natural descending drive.

\section{REMAINING CHALLENGES IN THERAPEUTIC ISMS}

While the applications of ISMS to promote activity and functional recovery is very promising, several technical hurdles must be overcome prior to widespread clinical adoption. The longterm stability of stimulating electrodes within the spinal cord must be demonstrated, as negative tissue responses are common following implantation of electrodes within the central nervous system (Shain et al., 2003; Spataro et al., 2005). Fortunately, delivery of stimulation may be less sensitive than recording of neural signals via implanted probes, and animal studies of ISMS electrode longevity demonstrate only modest tissue response (Mushahwar et al., 2000; Bamford et al., 2010) with only gradual increases in stimulation thresholds (Kasten et al., 2013). Additional hardware challenges can likely leverage the success of clinical epidural stimulation, currently approved as a treatment for chronic pain (Foreman and Linderoth, 2012). This existing platform provides examples of implantable stimulators and electrodes placed in the vicinity of the spinal cord with long-term efficacy.

To maximize the success of ISMS, the future depends upon the development of better insight in to the physiologic and molecular mechanisms of activity whereby axonal or circuit function is improved. In turn, complete restoration of neural function is likely to be achieved only by combining ISMS with complimentary therapies. Individual treatments rarely demonstrate large functional improvements, particularly in the chronic phase of SCI, and in clinically-relevant injury models. For example, combinations of intensive rehabilitation, pharmacological treatment and epidural stimulation show promise following a staggered hemisection injury (Van Den Brand et al., 2012; but cf. Slawińska et al., 2012). To effect recovery following chronic contusive injuries to the spinal cord, combinations of therapeutic spinal stimulation (epidural or ISMS) and additional modalities will likely be required. Examples of these additional interventions include pharmacological therapy (Musienko et al., 2011), application of stem cell therapy near the injury site (Parr et al., 2008; Nutt et al., 2013), treatments to minimize scar formation or encourage axonal outgrowth (Qiu et al., 2002; Pearse et al., 2004) and myelination (Lu et al., 2002). Intraspinal stimulation may collaborate with all of these approaches by creating the necessary activity to promote long-term repair of the injured spinal cord.

\section{CONCLUSION}

Cervical ISMS holds tremendous potential for both directly reanimating forelimb movements as well as promoting long-term recovery of function after SCI. Building on substantial evidence for the importance of activity in nervous system development and recovery, therapeutic ISMS may provide the otherwise absent electrical activity needed for neuron survival, axon growth, and 
synaptic stability. The application of therapeutic stimulation to the spinal cord distal to a lesion may therefore be critical in promoting repair of spinal circuits following injury, either alone or in combination with other rehabilitative and pharmacological interventions.

\section{ACKNOWLEDGMENTS}

Sarah E. Mondello is supported by the Sackler Scholars in Biophysics Postdoctoral Fellowship, and the Center for Sensorimotor Neural Engineering (CNSE), a National Science Foundation Engineering Research Center (EEC-1028725). Philip J. Horner is a member of the UW Institute for Stem Cell and Regenerative Medicine. Additional funding for this work was provided by an NIH/NINDS EUREKA award to Philip J. Horner \& Chet T. Moritz (1R01NS066357), a DARPA Young Faculty Award (D12AP00251), a Neilsen Foundation Pilot Research Grant (259314), and a Paul G. Allen Family Foundation grant to Chet T. Moritz.

\section{REFERENCES}

Al-Majed, A. A., Brushart, T. M., and Gordon, T. (2000a). Electrical stimulation accelerates and increases expression of BDNF and trkB mRNA in regenerating rat femoral motoneurons. Eur. J. Neurosci. 12, 4381-4390. doi: 10.1111/j.14609568.2000.01341.x

Al-Majed, A. A., Neumann, C. M., Brushart, T. M., and Gordon, T. (2000b). Brief electrical stimulation promotes the speed and accuracy of motor axonal regeneration. J. Neurosci. 20, 2602-2608.

Al-Majed, A. A., Tam, S. L., and Gordon, T. (2004). Electrical stimulation accelerates and enhances expression of regeneration-associated genes in regenerating rat femoral motoneurons. Cell. Mol. Neurobiol. 24, 379-402. doi: 10.1023/B:CEMN.0000022770.66463.f7

Anderson, K. D. (2004). Targeting recovery: priorities of the spinal cord-injured population. J. Neurotrauma 21, 1371-1383. doi: 10.1089/neu.2004.21.1371

Balice-Gordon, R. J., and Lichtman, J. W. (1994). Long-term synapse loss induced by focal blockade of postsynaptic receptors. Nature 372, 519-524. doi: $10.1038 / 372519 \mathrm{a} 0$

Bamford, J. A., Todd, K. G., and Mushahwar, V. K. (2010). The effects of intraspinal microstimulation on spinal cord tissue in the rat. Biomaterials 31, 5552-5563. doi: 10.1016/j.biomaterials.2010.03.051

Barbeau, H., Ladouceur, M., Mirbagheri, M. M., and Kearney, R. E. (2002). The effect of locomotor training combined with functional electrical stimulation in chronic spinal cord injured subjects: walking and reflex studies. Brain Res. Brain Res. Rev. 40, 274-291. doi: 10.1016/S0165-0173(02)00210-2

Bareyre, F. M., Kerschensteiner, M., Raineteau, O., Mettenleiter, T. C., Weinmann, O., and Schwab, M. E. (2004). The injured spinal cord spontaneously forms a new intraspinal circuit in adult rats. Nat. Neurosci. 7, 269-277. doi: 10.1038/nn1195

Behrman, A. L., Nair, P. M., Bowden, M. G., Dauser, R. C., Herget, B. R., Martin, J. B., et al. (2008). Locomotor training restores walking in a nonambulatory child with chronic, severe, incomplete cervical spinal cord injury. Phys. Ther. 88, 580-590. doi: 10.2522/ptj.20070315

Borodinsky, L. N., Belgacem, Y. H., and Swapna, I. (2012). Electrical activity as a developmental regulator in the formation of spinal cord circuits. Curr. Opin. Neurobiol. 22, 624-630. doi: 10.1016/j.conb.2012.02.004

Brushart, T. M., Hoffman, P. N., Royall, R. M., Murinson, B. B., Witzel, C., and Gordon, T. (2002). Electrical stimulation promotes motoneuron regeneration without increasing its speed or conditioning the neuron. J. Neurosci. 22, 6631-6638.

Brushart, T. M., Jari, R., Verge, V., Rohde, C., and Gordon, T. (2005). Electrical stimulation restores the specificity of sensory axon regeneration. Exp. Neurol. 194, 221-229. doi: 10.1016/j.expneurol.2005.02.007

Brus-Ramer, M., Carmel, J. B., Chakrabarty, S., and Martin, J. H. (2007). Electrical stimulation of spared corticospinal axons augments connections with ipsilateral spinal motor circuits after injury. J. Neurosci. 27, 13793-13801. doi: 10.1523/JNEUROSCI.3489-07.2007
Buffelli, M., Burgess, R. W., Feng, G., Lobe, C. G., Lichtman, J. W., and Sanes, J. R. (2003). Genetic evidence that relative synaptic efficacy biases the outcome of synaptic competition. Nature 424, 430-434. doi: 10.1038/nature01844

Carmel, J. B., Berrol, L. J., Brus-Ramer, M., and Martin, J. H. (2010). Chronic electrical stimulation of the intact corticospinal system after unilateral injury restores skilled locomotor control and promotes spinal axon outgrowth. J. Neurosci. 30, 10918-10926. doi: 10.1523/JNEUROSCI.1435-10.2010

Courtine, G., Song, B., Roy, R. R., Zhong, H., Herrmann, J. E., Ao, Y., et al. (2008). Recovery of supraspinal control of stepping via indirect propriospinal relay connections after spinal cord injury. Nat. Med. 14, 69-74. doi: 10.1038/nm1682

Cox, S. B., Woolsey, T. A., and Rovainen, C. M. (1993). Localized dynamic changes in cortical blood flow with whisker stimulation corresponds to matched vascular and neuronal architecture of rat barrels. J. Cereb. Blood Flow Metab. 13, 899-913. doi: $10.1038 /$ jcbfm. 1993.113

Edgerton, V. R., and Harkema, S. (2011). Epidural stimulation of the spinal cord in spinal cord injury: current status and future challenges. Expert Rev. Neurother. 11, 1351-1353. doi: 10.1586/ern.11.129

Fenrich, K. K., and Rose, P. K. (2009). Spinal interneuron axons spontaneously regenerate after spinal cord injury in the adult feline. J. Neurosci. 29, 12145-12158. doi: 10.1523/JNEUROSCI.0897-09.2009

Foreman, R. D., and Linderoth, B. (2012). Neural mechanisms of spinal cord stimulation. Int. Rev. Neurobiol. 107, 87-119. doi: 10.1016/B978-0-12-4047068.00006-1

Fox, E. J., Tester, N. J., Phadke, C. P., Nair, P. M., Senesac, C. R., Howland, D. R., et al. (2010). Ongoing walking recovery 2 years after locomotor training in a child with severe incomplete spinal cord injury. Phys. Ther. 90, 793-802. doi: 10.2522/ptj.20090171

Gerasimenko, Y., Roy, R. R., and Edgerton, V. R. (2008). Epidural stimulation: Comparison of the spinal circuits that generate and control locomotion in rats, cats and humans. Exp. Neurol. 209, 417-425. doi: 10.1016/j.expneurol.2007.07.015

Giszter, S. F., Mussa-Ivaldi, F. A., and Bizzi, E. (1993). Convergent force fields organized in the frog's spinal cord. J. Neurosci. 13, 467-491.

Goldberg, J. L., Espinosa, J. S., Xu, Y., Davidson, N., Kovacs, G. T., and Barres, B. A. (2002). Retinal ganglion cells do not extend axons by default: promotion by neurotrophic signaling and electrical activity. Neuron 33, 689-702. doi: 10.1016/S0896-6273(02)00602-5

Grumbles, R. M., Liu, Y., Thomas, C. M., Wood, P. M., and Thomas, C. K. (2013). Acute stimulation of transplanted neurons improves motoneuron survival, axon growth, and muscle reinnervation. J. Neurotrauma 30, 1062-1069. doi: 10.1089/neu.2012.2797

Hanson, M. G., and Landmesser, L. T. (2006). Increasing the frequency of spontaneous rhythmic activity disrupts pool-specific axon fasciculation and pathfinding of embryonic spinal motoneurons. J. Neurosci. 26, 12769-12780. doi: 10.1523/JNEUROSCI.4170-06.2006

Harder, D. R., Roman, R. J., Gebremedhin, D., Birks, E. K., and Lange, A. R. (1998). A common pathway for regulation of nutritive blood flow to the brain: arterial muscle membrane potential and cytochrome P450 metabolites. Acta Physiol. Scand. 164, 527-532.

Harkema, S., Gerasimenko, Y., Hodes, J., Burdick, J., Angeli, C., Chen, Y., et al. (2011). Effect of epidural stimulation of the lumbosacral spinal cord on voluntary movement, standing, and assisted stepping after motor complete paraplegia: a case study. Lancet 377, 1938-1947. doi: 10.1016/S0140-6736 (11)60547-3

Hartshorn, D. O., Miller, J. M., and Altschuler, R. A. (1991). Protective effect of electrical stimulation in the deafened guinea pig cochlea. Otolaryngol. Head Neck Surg. 104, 311-319.

Herman, R., He, J., D’luzansky, S., Willis, W., and Dilli, S. (2002). Spinal cord stimulation facilitates functional walking in a chronic, incomplete spinal cord injured. Spinal Cord 40, 65-68. doi: 10.1038/sj.sc.3101263

Houle, J. D., Tom, V. J., Mayes, D., Wagoner, G., Phillips, N., and Silver, J. (2006). Combining an autologous peripheral nervous system "bridge" and matrix modification by chondroitinase allows robust, functional regeneration beyond a hemisection lesion of the adult rat spinal cord. J. Neurosci. 26, 7405-7415. doi: 10.1523/JNEUROSCI.1166-06.2006

Iadecola, C., and Nedergaard, M. (2007). Glial regulation of the cerebral microvasculature. Nat. Neurosci. 10, 1369-1376. doi: 10.1038/nn2003

Ichiyama, R. M., Gerasimenko, Y. P., Zhong, H., Roy, R. R., and Edgerton, V. R. (2005). Hindlimb stepping movements in complete spinal rats induced 
by epidural spinal cord stimulation. Neurosci. Lett. 383, 339-344. doi: 10.1016/j.neulet.2005.04.049

Jablonka, S., Beck, M., Lechner, B. D., Mayer, C., and Sendtner, M. (2007). Defective $\mathrm{Ca} 2+$ channel clustering in axon terminals disturbs excitability in motoneurons in spinal muscular atrophy. J. Cell Biol. 179, 139-149. doi: $10.1083 /$ jcb. 200703187

Jung, R., Belanger, A., Kanchiku, T., Fairchild, M., and Abbas, J. J. (2009). Neuromuscular stimulation therapy after incomplete spinal cord injury promotes recovery of interlimb coordination during locomotion. J. Neural Eng. 6:055010. doi: 10.1088/1741-2560/6/5/055010

Kasten, M. R., Sunshine, M. D., and Moritz, C. T. (2012). "Cervical intraspinal microstimulation improves forelimb motor recovery after spinal contusion injury," in International Functional Electrical Stimulation Society, (Banff, AB).

Kasten, M. R., Sunshine, M. D., Secrist, E. S., Horner, P. J., and Moritz, C. T. (2013). Therapeutic intraspinal microstimulation improves forelimb function after cervical contusion injury. J. Neural Eng. 10:044001. doi: 10.1088/17412560/10/4/044001

Leake, P. A., Hradek, G. T., Rebscher, S. J., and Snyder, R. L. (1991). Chronic intracochlear electrical stimulation induces selective survival of spiral ganglion neurons in neonatally deafened cats. Hear. Res. 54, 251-271. doi: 10.1016/03785955(91)90120-X

Lemay, M. A., and Grill, W. M. (2004). Modularity of motor output evoked by intraspinal microstimulation in cats. J. Neurophysiol. 91, 502-514. doi: 10.1152/jn.00235.2003

Leybaert, L. (2005). Neurobarrier coupling in the brain: a partner of neurovascular and neurometabolic coupling? J. Cereb. Blood Flow Metab. 25, 2-16. doi: 10.1038/sj.jcbfm.9600001

Lohmann, C., Myhr, K. L., and Wong, R. O. (2002). Transmitter-evoked local calcium release stabilizes developing dendrites. Nature 418, 177-181. doi: 10.1038 /nature 00850

Lousteau, R. J. (1987). Increased spiral ganglion cell survival in electrically stimulated, deafened guinea pig cochleae. Laryngoscope 97, 836-842. doi: 10.1288/00005537-198707000-00012

Lu, J., Feron, F., Mackay-Sim, A., and Waite, P. M. (2002). Olfactory ensheathing cells promote locomotor recovery after delayed transplantation into transected spinal cord. Brain 125, 14-21. doi: 10.1093/brain/awf014

Malone, M., Gary, D., Yang, I. H., Miglioretti, A., Houdayer, T., Thakor, N., et al. (2013). Neuronal activity promotes myelination via a cAMP pathway. Glia 61, 843-854. doi: 10.1002/glia.22476

Mckenna, J. E., and Whishaw, I. Q. (1999). Complete compensation in skilled reaching success with associated impairments in limb synergies, after dorsal column lesion in the rat. J. Neurosci. 19, 1885-1894.

Mctigue, D. M., Horner, P. J., Stokes, B. T., and Gage, F. H. (1998). Neurotrophin3 and brain-derived neurotrophic factor induce oligodendrocyte proliferation and myelination of regenerating axons in the contused adult rat spinal cord. J. Neurosci. 18, 5354-5365.

Mirbagheri, M. M., Ladouceur, M., Barbeau, H., and Kearney, R. E. (2002). The effects of long-term FES-assisted walking on intrinsic and reflex dynamic stiffness in spastic spinal-cord-injured subjects. IEEE Trans. Neural Syst. Rehabil. Eng. 10, 280-289. doi: 10.1109/TNSRE.2002.806838

Morimoto, T., Jeffrey, L. G., and Ephraim, F. T. (2012). "Chapter Two - role of electrical activity of neurons for neuroprotection," in International Review of Neurobiology, eds J. L. Goldberg and E. F. Trakhtenberg (London; Amsterdam; Oxford; Waltham; San Diego: Academic Press), 19-38.

Moritz, C. T., Lucas, T. H., Perlmutter, S. I., and Fetz, E. E. (2007). Forelimb movements and muscle responses evoked by microstimulation of cervical spinal cord in sedated monkeys. J. Neurophysiol. 97, 110-120. doi: 10.1152/jn. 00414.2006

Mushahwar, V. K., Aoyagi, Y., Stein, R. B., and Prochazka, A. (2004). Movements generated by intraspinal microstimulation in the intermediate gray matter of the anesthetized, decerebrate, and spinal cat. Can. J. Physiol. Pharmacol. 82, 702-714. doi: 10.1139/y04-079

Mushahwar, V. K., Collins, D. F., and Prochazka, A. (2000). Spinal cord microstimulation generates functional limb movements in chronically implanted cats. Exp. Neurol. 163, 422-429. doi: 10.1006/exnr.2000.7381

Mushahwar, V. K., Gillard, D. M., Gauthier, M. J., and Prochazka, A. (2002). Intraspinal micro stimulation generates locomotor-like and feedbackcontrolled movements. IEEE Trans. Neural Syst. Rehabil. Eng. 10, 68-81. doi: 10.1109/TNSRE.2002.1021588
Mushahwar, V. K., and Horch, K. W. (1998). Selective activation and graded recruitment of functional muscle groups through spinal cord stimulation. Ann. N.Y. Acad. Sci. 860, 531-535. doi: 10.1111/j.1749-6632.1998.tb09096.x

Musienko, P., Van Den Brand, R., Marzendorfer, O., Roy, R. R., Gerasimenko, Y., Edgerton, V. R., et al. (2011). Controlling specific locomotor behaviors through multidimensional monoaminergic modulation of spinal circuitries. J. Neurosci. 31, 9264-9278. doi: 10.1523/JNEUROSCI.5796-10.2011

NSCISC. (2013). Spinal Cord Injury Facts and Figures at a Glance [Online]. Birmingham: The National Spinal Cord Injury Statistical Center. Available online at: https://www.nscisc.uab.edu/

Nutt, S. E., Chang, E. A., Suhr, S. T., Schlosser, L. O., Mondello, S. E., Moritz, C. T., et al. (2013). Caudalized human iPSC-derived neural progenitor cells produce neurons and glia but fail to restore function in an early chronic spinal cord injury model. Exp. Neurol. 248, 491-503. doi: 10.1016/j.expneurol.2013.07.010

Parr, A. M., Kulbatski, I., Zahir, T., Wang, X., Yue, C., Keating, A., et al. (2008). Transplanted adult spinal cord-derived neural stem/progenitor cells promote early functional recovery after rat spinal cord injury. Neuroscience 155, 760-770. doi: 10.1016/j.neuroscience.2008.05.042

Pearse, D. D., Pereira, F. C., Marcillo, A. E., Bates, M. L., Berrocal, Y. A., Filbin, M. T., et al. (2004). cAMP and Schwann cells promote axonal growth and functional recovery after spinal cord injury. Nat. Med. 10, 610-616. doi: 10.1038/nm1056

Petkau, T. L., Neal, S. J., Milnerwood, A., Mew, A., Hill, A. M., Orban, P., et al. (2012). Synaptic dysfunction in progranulin-deficient mice. Neurobiol. Dis. 45, 711-722. doi: 10.1016/j.nbd.2011.10.016

Petoukhov, E., Fernando, S., Mills, F., Shivji, F., Hunter, D., Krieger, C., et al. (2013). Activity-dependent secretion of progranulin from synapses. J. Cell Sci. 126, 5412-5421. doi: 10.1242/jcs.132076

Pizzorusso, T., Medini, P., Berardi, N., Chierzi, S., Fawcett, J. W., and Maffei, L. (2002). Reactivation of ocular dominance plasticity in the adult visual cortex. Science 298, 1248-1251. doi: 10.1126/science.1072699

Qiu, J., Cai, D., Dai, H., Mcatee, M., Hoffman, P. N., Bregman, B. S., et al. (2002). Spinal axon regeneration induced by elevation of cyclic AMP. Neuron 34, 895-903. doi: 10.1016/S0896-6273(02)00730-4

Salimi, I., and Martin, J. H. (2004). Rescuing transient corticospinal terminations and promoting growth with corticospinal stimulation in kittens. J. Neurosci. 24, 4952-4961. doi: 10.1523/JNEUROSCI.0004-04.2004

Schrimsher, G. W., and Reier, P. J. (1992). Forelimb motor performance following cervical spinal cord contusion injury in the rat. Exp. Neurol. 117, 287-298. doi: 10.1016/0014-4886(92)90138-G

Shain, W., Spataro, L., Dilgen, J., Haverstick, K., Retterer, S., Isaacson, M., et al. (2003). Controlling cellular reactive responses around neural prosthetic devices using peripheral and local intervention strategies. IEEE Trans. Neural Syst. Rehabil. Eng. 11, 186-188. doi: 10.1109/TNSRE.2003.814800

Shen, S., Wiemelt, A. P., Mcmorris, F. A., and Barres, B. A. (1999). Retinal ganglion cells lose trophic responsiveness after axotomy. Neuron 23, 285-295. doi: 10.1016/S0896-6273(00)80780-1

Slawińska, U., Rossignol, S., Bennett, D. J., Schmidt, B. J., Frigon, A., Fouad, K. et al. (2012). Comment on "Restoring voluntary control of locomotion after paralyzing spinal cord injury." Science 338:328. doi: 10.1126/science.1226082

Spataro, L., Dilgen, J., Retterer, S., Spence, A. J., Isaacson, M., Turner, J. N., et al. (2005). Dexamethasone treatment reduces astroglia responses to inserted neuroprosthetic devices in rat neocortex. Exp. Neurol. 194, 289-300. doi: 10.1016/j.expneurol.2004.08.037

Spitzer, N. C. (2006). Electrical activity in early neuronal development. Nature 444, 707-712. doi: 10.1038/nature05300

Sunshine, M. D., Cho, F. S., Lockwood, D. R., Fechko, A. S., Kasten, M. R., and Moritz, C. T. (2013). Cervical intraspinal microstimulation evokes robust forelimb movements before and after injury. J. Neural Eng. 10:036001. doi: 10.1088/1741-2560/10/3/036001

Tan, Y.-W., Zhang, S.-J., Hoffmann, T., and Bading, H. (2012). Increasing levels of wild-type CREB up-regulates several activity-regulated inhibitor of death (AID) genes and promotes neuronal survival. BMC Neurosci. 13:48. doi: 10.1186/14712202-13-48

Tapia, L., Milnerwood, A., Guo, A., Mills, F., Yoshida, E., Vasuta, C., et al. (2011). Progranulin deficiency decreases gross neural connectivity but enhances transmission at individual synapses. J. Neurosci. 31, 11126-11132. doi: 10.1523/JNEUROSCI.6244-10.2011

Tresch, M. C., and Bizzi, E. (1999). Responses to spinal microstimulation in the chronically spinalized rat and their relationship to spinal systems activated 
by low threshold cutaneous stimulation. Exp. Brain Res. 129, 401-416. doi: 10.1007/s002210050908

Van Den Brand, R., Heutschi, J., Barraud, Q., Digiovanna, J., Bartholdi, K., Huerlimann, M., et al. (2012). Restoring voluntary control of locomotion after paralyzing spinal cord injury. Science 336, 1182-1185. doi: 10.1126/science. 1217416

Wang, D., Ichiyama, R. M., Zhao, R., Andrews, M. R., and Fawcett, J. W. (2011). Chondroitinase combined with rehabilitation promotes recovery of forelimb function in rats with chronic spinal cord injury. J. Neurosci. 31, 9332-9344. doi: 10.1523/JNEUROSCI.0983-11.2011

Yang, J. L., Lin, Y. T., Chuang, P. C., Bohr, V. A., and Mattson, M. P. (2013). BDNF and exercise enhance neuronal DNA repair by stimulating CREB-Mediated production of apurinic/apyrimidinic endonuclease 1. Neuromolecular Med. doi: 10.1007/s12017-013-8270-x. [Epub ahead of print].

Zhang, S. J., Steijaert, M. N., Lau, D., Schutz, G., Delucinge-Vivier, C., Descombes, P., et al. (2007). Decoding NMDA receptor signaling: identification of genomic programs specifying neuronal survival and death. Neuron 53, 549-562. doi: 10.1016/j.neuron.2007.01.025

Zheng, J. Q., Wan, J. J., and Poo, M. M. (1996). Essential role of filopodia in chemotropic turning of nerve growth cone induced by a glutamate gradient. J. Neurosci. 16, 1140-1149.
Zimmermann, J. B., Seki, K., and Jackson, A. (2011). Reanimating the arm and hand with intraspinal microstimulation. J. Neural Eng. 8:054001. doi: $10.1088 / 1741-2560 / 8 / 5 / 054001$

Conflict of Interest Statement: The authors declare that the research was conducted in the absence of any commercial or financial relationships that could be construed as a potential conflict of interest.

Received: 02 December 2013; paper pending published: 05 January 2014; accepted: 24 January 2014; published online: 27 February 2014.

Citation: Mondello SE, Kasten MR, Horner PJ and Moritz CT (2014) Therapeutic intraspinal stimulation to generate activity and promote long-term recovery. Front. Neurosci. 8:21. doi: 10.3389/fnins.2014.00021

This article was submitted to Neuroprosthetics, a section of the journal Frontiers in Neuroscience.

Copyright (C) 2014 Mondello, Kasten, Horner and Moritz. This is an open-access article distributed under the terms of the Creative Commons Attribution License (CC BY). The use, distribution or reproduction in other forums is permitted, provided the original author(s) or licensor are credited and that the original publication in this journal is cited, in accordance with accepted academic practice. No use, distribution or reproduction is permitted which does not comply with these terms. 